\title{
FLEXURAL FATIGUE OF PRE-CRACKED PLASTIC FIBRE REINFORCED CONCRETE: EXPERIMENTAL STUDY AND NUMERICAL MODELING
}

\author{
Debora Martinello Carlesso ${ }^{\mathrm{a} *} \quad$ (debcarlesso@gmail.com), Sergio Cavalaro ${ }^{\mathrm{b}}$ \\ (S.Cavalaro@lboro.ac.uk), Albert de la Fuente ${ }^{a}$ (albert.de.la.fuente@ upc.edu) \\ a: Polytechnic University of Catalonia - BarcelonaTECH, Barcelona, Spain \\ b: Loughborough University, Loughborough, United Kingdom \\ *: Corresponding author
}

\begin{abstract}
The objective of this paper is to analyse the mechanical behaviour of polypropylene fibre reinforced concrete subjected to load cycles and propose a model to predict the crack-opening increase and mechanical performance evolution over the cycles. Fatigue tests were performed in pre-cracked specimens with two fibre types and contents to assess the evolution of the crack-opening for prescribed numbers of load cycles. The residual flexural tensile strength was assessed before and after these tests to estimate the impact of the cycles in the remaining resistant capacity of the specimens. Results suggest that the mechanism of crack propagation is independent of the fibre type and content. The accumulated damage due to the cycles produces an offset in the quasi-static residual tensile strength curve. These findings underpin the proposal of a model to predict the evolution of the crack-opening and the remaining resistant capacity. An optimisation procedure is proposed to derive the model parameters using a limited number of initial load cycles.
\end{abstract}

\section{KEYWORDS}

Fatigue; fibre reinforced concrete; pre-cracking; polypropylene fibre

\section{INTRODUCTION}

Fibre-reinforced concrete (FRC) elements without traditional reinforcement are extensively used in applications exposed to cyclic loadings, such as tunnel linings [1-5], pavements [6], bridge deck overlays $[7,8]$, wind energy towers $[9,10]$ and offshore structures $[11,12]$. The cyclic load produces tensile stresses that can lead to crack initiation and propagation [13,14], compromising the mechanical performance and durability, and eventually bringing about noncompliance with service or limit state requirements [15] [16,17]. FRC structures can work in the cracked condition during their service life either because they were designed to do so or because accidental, transient or thermal-hygrometric actions induce cracks. The loss of performance and potential collapse caused by fatigue are significantly accelerated if cracks are already present in the structure.

The understanding of the damage propagation is the basis for the proposal of numerical models to estimate the loss of performance over the load cycles, which enable the prediction of the fatigue life in concrete structures $[18,19][20,21]$ and should be particularly important in precracked elements reinforced only with fibres. The literature includes few studies on the behaviour of pre-cracked FRC under cyclic direct tension [22-25] [26] or flexural [20,27-30] [31] [32-35] $[36,37]$ load.

Germano et al. [27] studied the fatigue behaviour of steel fibre reinforced concrete (SFRC) and found that the crack-opening range and crack-opening increment per cycle govern the fatigue 
life. González et al. [20] analysed the residual tensile strength of SFRC after cyclic loading and observed a progressive reduction in stiffness, caused by cracking in the fibre-matrix interface that leads to a reduction of fibre-concrete bond and residual strength. The numerical models derived from these studies are generally based on regressions of the experimental results and could hardly be generalised to other conditions. Owing to the lack of experimental results and accepted models, codes and guidelines for the design of FRC structures are either vague or unclear on how to account for the fatigue in the design. This poses a potential hazard for users of FRC structures subjected to a significant number of load cycles.

Assumptions and conclusions from studies about SFRC cannot be directly generalised to plastic fibre reinforced concrete (PFRC) due to the significant differences between the properties of these fibres. As summarised in Table 1, the literature provides limited information about the fatigue of PFRC. Although pre-cracked specimens were assessed in compression fatigue tests, only non-cracked specimens were tested in flexural fatigue tests and only 2 studies evaluate the postfatigue residual strength. Moreover, the empirical fatigue model found in the literature addresses the PFRC behaviour under cyclic compressive load, not flexural load.

Table 1 -Research about the fatigue of PFRC

\begin{tabular}{cccccc}
\hline Reference & $\begin{array}{c}\text { Compressive load } \\
\text { cycles }\end{array}$ & $\begin{array}{c}\text { Flexural load } \\
\text { cycles }\end{array}$ & $\begin{array}{c}\text { Pre-cracked } \\
\text { specimens }\end{array}$ & $\begin{array}{c}\text { Post-fatigue } \\
\text { residual behaviour }\end{array}$ & Fatigue model \\
\hline$[19]$ & $\mathrm{x}$ & & $\mathrm{x}$ & \\
\hline$[26]$ & $\mathrm{x}$ & $\mathrm{x}$ & & \\
\hline$[31]$ & & $\mathrm{x}$ & & & \\
\hline$[32-35]$ & & $\mathrm{x}$ & & $\mathrm{x}$ & \\
\hline$[36,37]$ & $\mathrm{x}$ & $\mathbf{x}$ & $\mathbf{x}$ & $\mathbf{x}$ \\
\hline This study & & $\mathbf{x}$ & & \\
\hline
\end{tabular}

Considering the surge in PFRC application with structural responsibility and the likelihood of finding elements with cracks in service, additional studies are needed to grasp the implications of the flexural fatigue of pre-cracked PFRC in terms of crack-opening evolution and residual flexural strength. Likewise, models are needed to predict the material performance in terms of the evolution of crack-opening and residual resistant capacity after the cycles. This study addresses both needs. An extensive experimental study encompassing quasi-static and dynamic tests of PFRC assessed the influence of the flexural load cycles on the mechanical performance of specimens. Results support the proposal of a semi-empirical model to predict the crack-opening evolution and the remaining flexural strength. This research provides knowledge, singular experimental results and a conceptual model for the behaviour of PPFRC under flexural load cycles that can inform future FRC design codes.

\section{EXPERIMENTAL PROGRAM}

The variables analysed in the experimental program were the fibre type, fibre content, and maximum number of load cycles $\left(N_{\max }\right)$ applied during the fatigue test. Fresh- and hardened-state properties were assessed. The flexural fatigue response was evaluated in terms of the evolution of crack mouth opening displacement (CMOD) over the load cycles. Then, specimens were tested under quasi-static flexural configuration to evaluate the influence of the cyclic loading on the residual flexural strength. Thereafter, the cracked surface of PFRC samples and the fibre failure mode were examined with an optical microscope. 
2.1. Mix design, casting and curing

Table 2 shows the PFRC compositions used in the experimental program, which should satisfy the structural requirements for typical applications in heavy-duty pavements, industrial floors, tunnel segmental lining and precast elements in general. All mixes contained Portland cement CEM I-52.5 R, limestone aggregates, sodium polycarboxylate ether-based superplasticiser and water/cement ratio of 0.40 . Two fibre contents were used to represent different levels of residual flexural strength. The first $\left(5 \mathrm{~kg} / \mathrm{m}^{3}\right.$ or $0.4 \%$ by volume) is expected to achieve an infracritical behaviour in bending according to the fib Model Code 2010 [46], with limited stress recovery between $f_{r 1}$ and $f_{r 3}$ (residual strengths correspondent to values of CMOD of 0.5 and 2.5 $\mathrm{mm}$, respectevely). The second $\left(10 \mathrm{~kg} / \mathrm{m}^{3}\right.$ or $0.8 \%$ by volume) is expected to achieve a nearly critical behaviour in bending according to the fib Model Code 2010 [46], with significant stress recovery between $f_{r 1}$ and $f_{r 3}$.

Table 2 - Mix proportion, fresh-state and control test results and their respective coefficient of variability

\begin{tabular}{|c|c|c|c|c|}
\hline & Composition & PF1-1.1C & PF1-1.6E & PF2-1.5E \\
\hline \multirow{7}{*}{ Materials } & Cement $\left(\mathrm{kg} / \mathrm{m}^{3}\right)$ & 421 & 420 & 420 \\
\hline & Water $\left(\mathrm{kg} / \mathrm{m}^{3}\right)$ & 168 & 168 & 168 \\
\hline & Sand $(0-4 \mathrm{~mm})\left(\mathrm{kg} / \mathrm{m}^{3}\right)$ & 862 & 860 & 860 \\
\hline & Coarse aggregate $(4-10 \mathrm{~mm})\left(\mathrm{kg} / \mathrm{m}^{3}\right)$ & 441 & 440 & 440 \\
\hline & Coarse aggregate $(10-20 \mathrm{~mm})\left(\mathrm{kg} / \mathrm{m}^{3}\right)$ & 491 & 490 & 490 \\
\hline & Superplasticizer $\left(\mathrm{kg} / \mathrm{m}^{3}\right)$ & 4.2 & 4.2 & 4.2 \\
\hline & Polypropylene fibres $\left(\mathrm{kg} / \mathrm{m}^{3}\right)$ & 5 & 10 & 10 \\
\hline \multirow{3}{*}{ Fresh state results } & Slump $(\mathrm{cm})$ & $9.5(37.2 \%)$ & $12.0(23.6 \%)$ & $3.0(27.2 \%)$ \\
\hline & Density $\left(\mathrm{kg} / \mathrm{m}^{3}\right)$ & $2402(0.4 \%)$ & $2405(0.0 \%)$ & $2401(0.3 \%)$ \\
\hline & Air content $(\%)$ & $2.2(3.1 \%)$ & $2.1(17.3 \%)$ & $3.0(2.7 \%)$ \\
\hline \multirow{2}{*}{ Control test results } & Compressive strength (MPa) & $64.5(9.9 \%)$ & $63.8(2.8 \%)$ & $53.6(6.7 \%)$ \\
\hline & Elastic modulus (MPa) & $37.1(4.4 \%)$ & $37.0(0.6 \%)$ & $38.1(4.2 \%)$ \\
\hline
\end{tabular}

The fibre PF1 was 48-mm long and was made of virgin polypropylene with specific gravity of $0.89-0.91 \mathrm{~g} / \mathrm{cm}^{3}$. Fibre PF2 was $60-\mathrm{mm}$ long and was made of polypropylene copolymer with specific gravity of $0.91 \mathrm{~g} / \mathrm{cm}^{3}$. Both had continuous embossing anchorage and were considered adequate for FRC with structural responsibility. Although polypropylene is a thermo-responsive polymer, literature reports melting and crystallisation temperatures of $116{ }^{\circ} \mathrm{C}$ and $162{ }^{\circ} \mathrm{C}$, respectively [41,42]. For that reason, no change in the mechanical response nor phase transition are expected at room temperature.

To reduce the number of trials considering the long duration of each fatigue test, the influence of the fibre content was assessed only for PF1 by comparing PF1-1.1C and PF1-1.6E with $5 \mathrm{~kg} / \mathrm{m}^{3}$ and $10 \mathrm{~kg} / \mathrm{m}^{3}$, respectively. Likewise, the influence of the fibre type was only assessed for the highest fibre content by comparing PF1-1.6E with $10 \mathrm{~kg} / \mathrm{m}^{3}$ of PF1 and the analogous PF2$1.5 \mathrm{E}$ with $10 \mathrm{~kg} / \mathrm{m}^{3}$ of PF2. The reduction of the fibre content from $10 \mathrm{~kg} / \mathrm{m}^{3}$ to $5 \mathrm{~kg} / \mathrm{m}^{3}$ entailed an increase in the content of other materials, although their relative proportion was kept the same. The criteria adopted here was to maintain such relative proportion in all mixes, thus ensuring as much as possible identical matrices. This implies differences in the fresh-state rheology of mixes induced by the fibre type and content.

The mixing process took place in a vertical-axis mixer with a nominal capacity of 501 . After homogenising all dry components (cement, sand and aggregates), water and superplasticizer were added to the mixer and, finally, fibres were added. Upon achieving a homogeneous mix, the freshstate properties were assessed and the following specimens were cast per composition: $\varnothing 150 \times 300$ 
$\mathrm{mm}^{2}$ cylinders for compressive strength and elastic modulus, and $150 \times 150 \times 600 \mathrm{~mm}^{3}$ prismatic beams for residual flexural strength and fatigue tests. After casting, the moulds were covered with a thin plastic sheet and left to cure at room temperature for 24 hours. Then, they were demoulded and stored in a climatic chamber at $20{ }^{\circ} \mathrm{C}$ and $95 \%-100 \%$ relative humidity until the date of the test.

\subsection{Experimental procedures}

\subsubsection{Control tests}

Slump, density and air content were characterised according to EN 12350-2:2009, EN 12350-6:2009 and EN 12350-7:2010, respectively. For each composition, compressive strength was measured in four cylinders in accordance to EN 12390-3:2009 and the elastic modulus was measured in three cylinders in accordance to the EN 12390-13:2014 using a universal compression testing machine IBERTEST MEH-3000 with a nominal maximum load capacity of 3,000 kN. The quasi-static flexural strength was measured following the EN 14651:2007 in three notched beams with a three-point bending test (3PBT) setup in an INSTRON hydraulic servo-controlled testing machine. A clip gauge placed at the notch of depth of $25 \mathrm{~mm}$ controlled the CMOD during the 3PBT. All quasi-static tests were performed at 28 days.

\subsubsection{Dynamic tests}

Fatigue tested beams followed the same configuration of the control tests bems. Figure 1 shows the schematic loading history of specimens subjected to the fatigue test and the equivalent quasi-static response. First, specimens were pre-cracked in 3PBT setup according to the procedure in EN 14651:2007. A constant CMOD rate of $0.05 \mathrm{~mm} / \mathrm{min}$ was applied up to a total CMOD of $0.5 \mathrm{~mm}$ (considered the service limit value in fib Model Code 2010 [46]). The force corresponding to this displacement was set as the maximum load in the fatigue test $\left(\mathrm{P}_{\mathrm{upp}}\right)$. The minimum load ( $\left.\mathrm{P}_{\text {low }}\right)$ during the cycles was defined by considering an amplitude ratio of $0.3\left(\mathrm{R}=\mathrm{P}_{\text {low }} / \mathrm{P}_{\text {upp }}=0.3\right)$. Immediately after pre-cracking and without removing the specimen from the testing machine, a sinusoidal cyclic load with a frequency of $6 \mathrm{~Hz}$ ranging from $\mathrm{P}_{\text {upp }}$ to $\mathrm{P}_{\text {low }}$ was applied, and the evolution of CMOD was recorded at every 500 cycles. $N_{\max }$ was either $1,000,000[28,47-51]$ or $2,000,000[34,36,52,53]$, which are a common reference for the assessment of the endurance limit in the literature. Upon reaching $N_{\max }$, the cyclic loading was interrupted, and the beams were immediately reloaded at a constant CMOD rate of $0.2 \mathrm{~mm} / \mathrm{min}$ up to failure. Notice that the clip gage was kept in place throughout the whole process so that the $0 \mathrm{~mm}$ refers to the condition found before pre-cracking. After failure, specimens were removed from the frame and separated in 2 halves for the assessment of the failure cross-section and manual counting of fibres. 


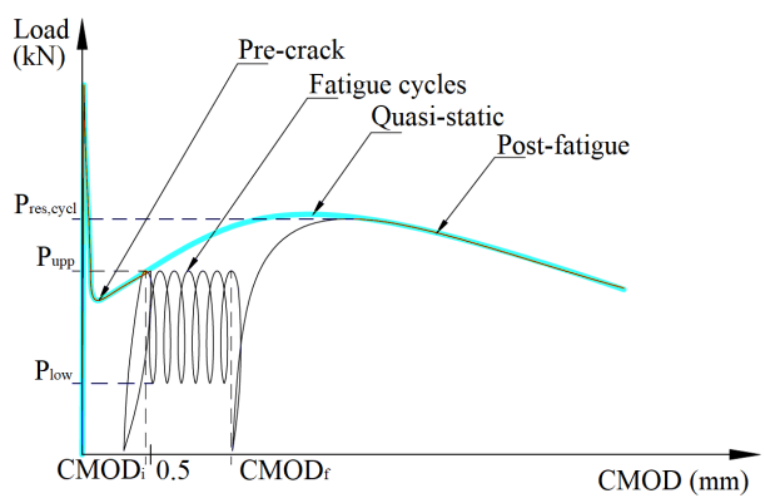

Figure 1 - Fatigue loading history

In total, seven specimens were tested for PF2-1.5E, and five specimens were tested for PF11.1C and PF1-1.6E, each. This number was based on the experimental programmes from other studies in the literature $[29,36,37,54]$ about the residual resistant strength after application load cycles. Owing to the limited availability of testing machines and the long duration of each test, the fatigue could not be assessed at the same age in all specimens. The specimens were tested in a period extending from 30 to 90 days since casting, alternating between mixes to minimise the influence of the age in the results. A variation of 5.5\% in quasi-static flexural strength was expected between 30 and 90 days based on the formulations from the Eurocode 2-1 (EN 1992-1-1).

\section{RESULTS AND DISCUSSION}

\subsection{Fresh state properties and mechanical characterisation}

Table 2 shows the average and the coefficient of variation (CV presented between parenthesis) for the slump, density, air content, compressive strength and elastic modulus of all mixes. The increase from $5 \mathrm{~kg} / \mathrm{m}^{3}$ of PF1 in PF1-1.1C to $10 \mathrm{~kg} / \mathrm{m}^{3}$ in PF1-1.6E did not have a statistically significant influence on the fresh-state properties, compressive strength and elastic modulus of the PFRC. By contrast, the change in the type of fibre from PF1 in PF1-1.6E to PF2 in PF2-1.5E led to a 4-fold reduction in the slump and 50\% increase in the air content, which might explain the $17 \%$ reduction observed in the compressive strength.

Table 3 presents the average residual flexural strengths $\left(f_{R 1 m}, f_{R 2 m}, f_{R 3 m}, f_{R 4 m}\right.$ corresponding to CMOD values of $0.5,1.5,2.5$ and $3.5 \mathrm{~mm}$, respectively), limit of proportionality ( $f_{L O P m}$ corresponding to the maximum strength within the range of $0.05 \mathrm{~mm}$ ), maximum post-cracking stress $\left(f_{P C, \text { max }}\right)$ and the respective CMOD $\left(\mathrm{CMOD}_{f P C, \max }\right)$ measured in the 3PBT. The table also includes the characteristic values of $f_{L O P}\left(f_{L O P k}\right)$ and the flexural residual strengths $f_{R I}\left(f_{R I k}\right)$ and $f_{R 3}$ $\left(f_{R 3 k}\right)$ related respectively with the service and ultimate limit states [46]. Figure 2 gathers the 3PBT average (continuous line) and envelope (hatched area) curves for PF1-1.1C and PF1-1.6E (a) and PF2-1.5E (b). All residual stresses presented in this paper were calculated considering an equivalent linear elastic non-cracked cross-section.

Table 3 - Average and characteristic 3PBT results and coefficient of variation in percentage and between parenthesis

\begin{tabular}{|c|c|c|c|c|c|c|c|c|c|c|c|c|}
\hline Comp. & $\begin{array}{l}f_{L O P m} \\
(\mathrm{MPa})\end{array}$ & $\begin{array}{l}f_{P C, \max } \\
(\mathrm{MPa})\end{array}$ & $\begin{array}{c}\text { CMOD }_{\text {fPC, } \max } \\
(\mathbf{m m})\end{array}$ & $\begin{array}{c}\mathbf{f}_{\mathrm{R} 1 \mathrm{~m}} \\
(\mathrm{MPa})\end{array}$ & $\begin{array}{c}\mathbf{f}_{\mathrm{R} 2 \mathrm{~m}} \\
(\mathrm{MPa})\end{array}$ & $\begin{array}{c}\mathbf{f}_{\mathrm{R} 3 \mathrm{~m}} \\
(\mathrm{MPa})\end{array}$ & $\begin{array}{c}\mathbf{f}_{\mathrm{R} 4 \mathrm{~m}} \\
(\mathrm{MPa})\end{array}$ & $\begin{array}{c}\mathbf{f}_{\mathrm{LOPk}} \\
(\mathrm{MPa})\end{array}$ & $\begin{array}{c}\mathbf{f}_{\mathrm{R} 1 \mathrm{k}} \\
(\mathrm{MPa})\end{array}$ & $\begin{array}{c}\mathbf{f}_{\mathrm{R} 3 \mathrm{k}} \\
(\mathrm{MPa})\end{array}$ & $\mathbf{f}_{\mathrm{R} 3 \mathrm{k}} / \mathbf{f}_{\mathrm{R} 1 \mathrm{k}}$ & $\begin{array}{l}\mathbf{f}_{\mathrm{R} 1 \mathrm{k}} / \\
\mathbf{f}_{\mathrm{LOPk}}\end{array}$ \\
\hline $\begin{array}{l}\text { PF1- } \\
1.1 \mathrm{C}\end{array}$ & $\begin{array}{l}5.21 \\
(7.2)\end{array}$ & $\begin{array}{c}2.22 \\
(41.8)\end{array}$ & 3.059 (10.8) & $\begin{array}{c}1.45 \\
(36.2)\end{array}$ & $\begin{array}{c}1.92 \\
(42.0)\end{array}$ & $\begin{array}{c}2.17 \\
(43.4)\end{array}$ & $\begin{array}{c}2.17 \\
(41.2)\end{array}$ & .76 & 0.59 & 0.62 & $1.1 \mathrm{c}^{*}$ & 0.1 \\
\hline
\end{tabular}




\begin{tabular}{|c|c|c|c|c|c|c|c|c|c|c|c|c|}
\hline $\begin{array}{c}\text { PF1- } \\
1.6 \mathrm{E}\end{array}$ & $\begin{array}{c}5.39 \\
(12.2)\end{array}$ & $\begin{array}{c}5.59 \\
(10.5)\end{array}$ & $2.919(4.9)$ & $\begin{array}{c}3.49 \\
(9.7)\end{array}$ & $\begin{array}{c}4.93 \\
(11.9)\end{array}$ & $\begin{array}{c}5.50 \\
(10.7)\end{array}$ & $\begin{array}{c}5.42 \\
(9.0)\end{array}$ & 4.25 & 2.93 & 4.54 & $1.6 \mathrm{e}^{*}$ & 0.7 \\
\hline $\begin{array}{c}\text { PF2- } \\
1.5 \mathrm{E}\end{array}$ & $\begin{array}{c}5.14 \\
(6.7)\end{array}$ & $\begin{array}{c}3.47 \\
(15.7)\end{array}$ & $3.994(0.0)$ & $\begin{array}{c}2.05 \\
(14.8)\end{array}$ & $\begin{array}{c}2.73 \\
(16.5)\end{array}$ & $\begin{array}{c}3.18 \\
(16.7)\end{array}$ & $\begin{array}{c}3.40 \\
(16.3)\end{array}$ & 4.61 & 1.55 & 2.31 & $1.5 \mathrm{e}^{*}$ & 0.3 \\
\hline
\end{tabular}

* Classification of the post-cracking strength based on Model Code 2010 [46]

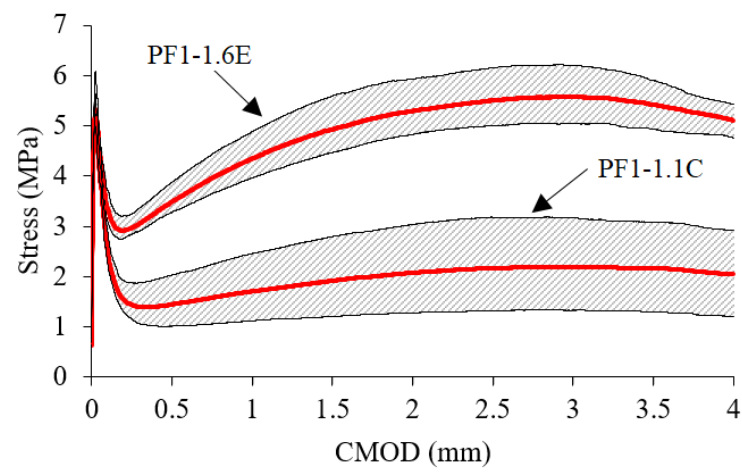

(a)

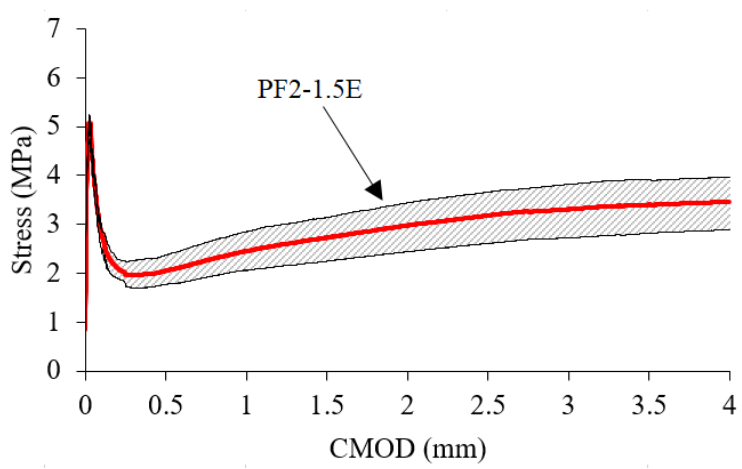

(b)

Figure 2 - Average and envelope of 3PBT results: (a) PF1-1.1C and PF1-1.6E, and (b) PF2.1.5E

The $f_{L O P m}$ is not significantly affected by the fibre content and type. Immediately after cracking, PFRCs exhibited a sudden stress drop indicating loss of stiffness. The minimum residual stress observed just after cracking was approximately 66\% (PF1-1.1C), 51\% (PF1-1.6E), and 57\% (PF2-1.5E) of $f_{P C, \max }$. The ductile behaviour and stress recovery are attributed to the contribution of the fibres [31,55]. PF1-1.1C showed a nearly stable post-cracking response while PF1-1.6E and PF2-1.5E showed an increase in stress when reaching higher CMOD values. Notice that the last part of the name of each mix represents their classification according to the Model Code 2010 [46], which depends on the ration $f_{R 3 k} / f_{R l k}$.

\subsection{Fatigue test: CMOD variation over cycles}

Table 4 summarises for each specimen the maximum number of cycles $\left(N_{\max }\right), P_{\text {upp }}, \mathrm{CMOD}$ for $P_{\text {upp }}$ at the first, $1,000,000$ and $2,000,000$ cycles $\left(\mathrm{CMOD}_{1}, \mathrm{CMOD}_{1 \mathrm{M}}\right.$ or $\mathrm{CMOD}_{2 \mathrm{M}}$, respectively). The table also shows the difference between $\mathrm{CMOD}_{1 \mathrm{M}}$ and $\mathrm{CMOD}_{1}(\triangle \mathrm{CMOD})$. To better illustrate the behaviour of the mixes, Figure $3 \mathrm{a}$ to $\mathrm{c}$ show the evolution of the CMOD measured at different cycles for $\mathrm{P}_{\mathrm{upp}}$, and Figure $3 \mathrm{~d}$ shows the schematic representation of the different stages possible during the fatigue test.

Table 4-Results of fatigue tests and post-fatigue quasi-static flexural strength

\begin{tabular}{|c|c|c|c|c|c|c|c|c|c|c|c|c|c|c|}
\hline \multirow[b]{2}{*}{ 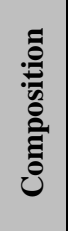 } & \multirow[b]{2}{*}{ : } & \multirow[b]{2}{*}{ 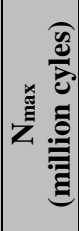 } & \multicolumn{7}{|c|}{ Fatigue test } & \multicolumn{5}{|c|}{ Post-fatigue quasi static } \\
\hline & & & 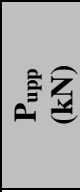 & $\stackrel{\hat{\varrho}}{\bar{g}}$ & 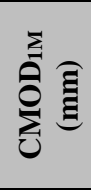 & 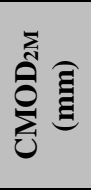 & $\sum_{\mathcal{y}}^{\hat{0}} \widehat{\Xi}$ & $\underline{\Xi}$ & อ & 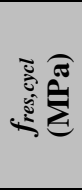 & हิ & 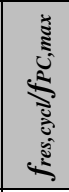 & $\begin{array}{l}\text { ट. } \\
\text { ồ } \\
\text { is } \\
\text { is }\end{array}$ & 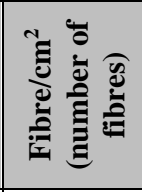 \\
\hline \multirow{5}{*}{$\begin{array}{l}\stackrel{U}{a} \\
\frac{1}{1} \\
\frac{1}{2}\end{array}$} & & 1 & 4. & 列 & - & - & 211 & & & 12 & 0.2 & .23 & 0.02 & \\
\hline & $\mathrm{PF}$ & 1 & 5 & 0.466 & 1.385 & - & (1) & 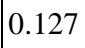 & 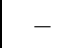 & 37 & 2.63 & .52 & 6 & 0.10 (0) \\
\hline & PF1-1.1C_ & 1 & 5.82 & 0574 & 2.036 & - & .462 & 0.194 & 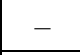 & 3.18 & 3.41 & 1.43 & 0.70 & 0. \\
\hline & PF1-1.1C & 2 & 4.43 & 0.477 & 1.749 & 1.899 & 1.272 & 0.166 & 0 & 2.69 & 3.41 & 1.21 & 0.63 & $0.44(83)$ \\
\hline & PF1-1.1C_2M-5 & 2 & 0.13 & 0.467 & 1.715 & 1.894 & 1.248 & 0.186 & 0.214 & 2.89 & 3.16 & 1.30 & 0.69 & 0.55 (104) \\
\hline 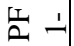 & PF1-1.6E_1M-1 & 1 & 8.41 & 0.490 & 2.542 & - & 2.052 & 0.313 & - & 5.08 & 3.55 & 0.91 & 0.64 & $0.05(150)$ \\
\hline
\end{tabular}


1

2

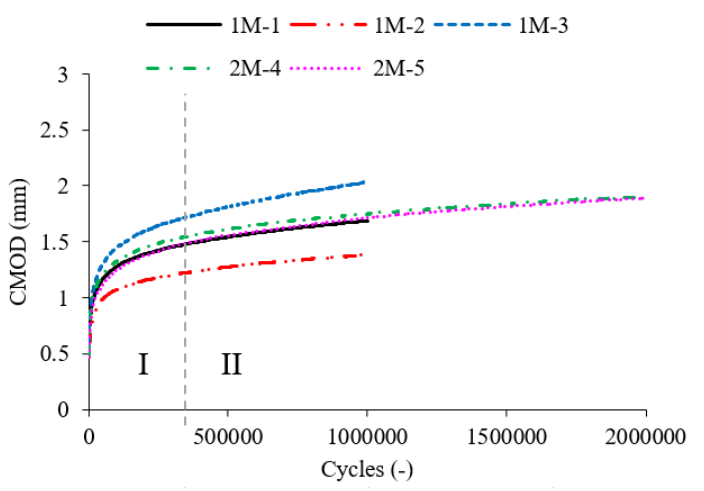

(a)

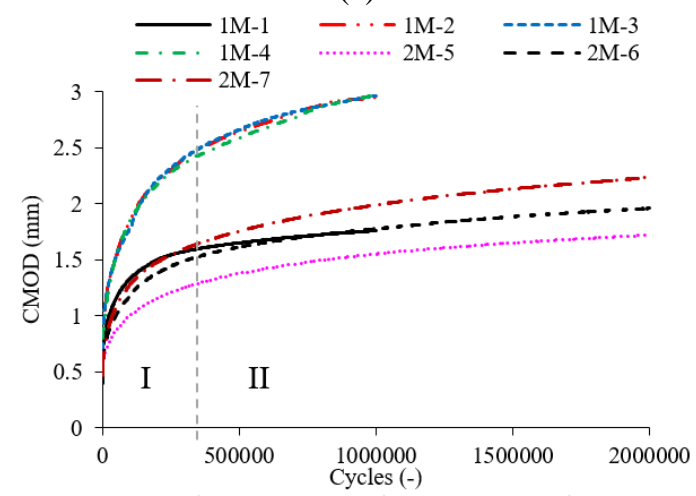

(c)

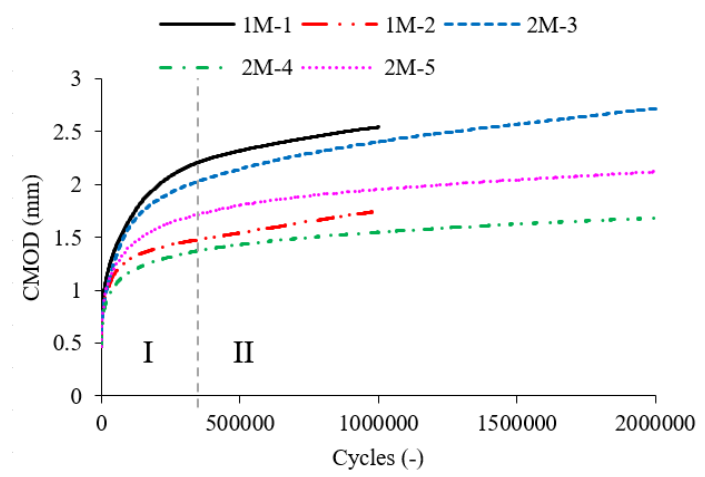

(b)

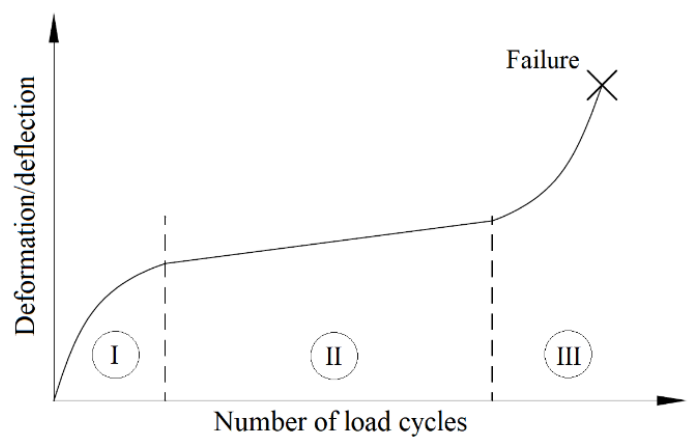

(d)

\begin{tabular}{|c|c|c|c|c|c|c|c|c|c|c|c|c|c|c|}
\hline & PF1-1.6E_1M-2 & 1 & 8.18 & 0.467 & 1.747 & - & 1.280 & 0.219 & - & 5.26 & 3.3 & 0.94 & 0.60 & $0.88(165)$ \\
\hline & PF1-1.6E_2M-3 & 2 & 9.60 & 0.491 & 2.403 & 2.718 & 1.912 & 0.275 & 0.335 & 5.56 & 3.82 & 0.99 & 0.66 & $0.95(179)$ \\
\hline & PF1-1.6E_2M-4 & 2 & 8.36 & 0.469 & 1.550 & 1.684 & 1.081 & 176 & 0.204 & 5.30 & 3.15 & 0.95 & 0.61 & $0.91(170)$ \\
\hline & PF1-1.6E_2M-5 & 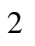 & 4.80 & 0.463 & 1.953 & 2.120 & 1.490 & 0.221 & 0.255 & 3.01 & 3.49 & 0.54 & 0.61 & $0.62(116)$ \\
\hline \multirow{7}{*}{ 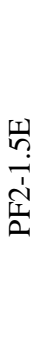 } & PF2-1 & 1 & 5 & 0.473 & 1.764 & - & 1.291 & 0.149 & - & 4.37 & 4.52 & 1.26 & 0.44 & $0.48(91)$ \\
\hline & PF2-1.5E_1M-2 & 1 & 5 & 0.475 & 2.947 & - & 2.472 & 0.339 & - & 3.57 & 5.33 & 1.03 & 0.54 & $0.44(83)$ \\
\hline & PF2-1.5E_1M-3 & 1 & 5 & 0.449 & 2.966 & - & 2.516 & 0.313 & - & 3.3 & 5.15 & 0.95 & 0.58 & $0.51(96)$ \\
\hline & PF2-1.5E_1M-4 & 1 & 4.71 & 0.471 & 2.969 & - & 2.498 & 6 & - & 3.08 & 4.97 & 0.89 & 0.59 & 79) \\
\hline & PF2-1.5E & 2 & 7.14 & 0.51 & 1.552 & 1.723 & 1.042 & 0.088 & 0.103 & 5.41 & 4.21 & 1.56 & 0.51 & $0.77(145)$ \\
\hline & PF2-1.5E_2M-6 & 2 & 3.70 & 0.398 & 1.777 & 1.959 & 1.379 & 0.146 & 0.155 & 2.94 & 5.01 & 0.85 & 0.48 & $0.46(86)$ \\
\hline & PF2-1.5E_2M-7 & 2 & 5.63 & 0.471 & 1.991 & 2.236 & 1.519 & 0.168 & 0.191 & 3.77 & 5.97 & 1.09 & 0.57 & $0.55(104)$ \\
\hline
\end{tabular}

Figure 3-CMOD evolution with cycles: (a) PF1-1.1C, (b) PF1-1.6E, (c) PF2-1.5E and (d) schematic representation of possible stages during the fatigue test based on [25][56]

The evolution of the CMOD during the fatigue test of all specimens in the experimental programme undergoes 2 stages. In Stage I, the CMOD increases rapidly but with a decreasing rate up to approximately 350,000 cycles. Then, specimens enter Stage II, showing a linear relationship between the number of the cycle and the CMOD increment. None of the specimens reached Stage III, where the CMOD would grow with an increasing rate, potentially leading to the failure of the specimen [25][56], as shown in Figure 3d. Despite the high load value applied during the fatigue 
test (equal to the resistant capacity of the pre-cracked specimen for $0.5 \mathrm{~mm}$ CMOD), the absence of Stage III may be attributed to the hardening experienced by the PPFRC in the post-cracking stage, which creates an additional barrier to the CMOD increment. Notice that the final CMOD after the fatigue test is smaller than the CMOD corresponding to the maximum residual flexural stress in the control quasi-static tests.

The pre-cracking process executed just before the fatigue test compromises the capacity of the matrix to transmit tensile forces in part of the cross-section. The difference in elastic modulus of fibre and matrix implies that an increment in the crack-opening is needed to activate the fibres that take over the transmission of tensile forces in such regions [19]. This - combined with the high $\mathrm{P}_{\text {upp }}$ in comparison with the resistant capacity of the cross-section at the beginning of the fatigue test - favours crack propagation through the matrix and produces the rapid initial increment of CMOD in Stage I. Additional increases in CMOD further activate the fibres and elevate the cross-sectional resistant capacity that becomes progressively bigger than $\mathrm{P}_{\text {upp }}$, thus leading to the reduction in the CMOD increment over the cycles at the end of Stage I. Additional microcracks may develop in the fibre-matrix interface and merge into macrocracks [14] resulting in increase in damage by fibre debonding and pull-out over the cycles. This gradual damage is responsible for the linear CMOD increase observed in Stage II. As mentioned before, 2,000,000 cycles were not enough to produce significant fibre pull-out in the cross-section and accumulate damage to trigger stage III in the mixes characterised in this experimental program.

The Welch's $t$-test was performed to determine whether the average CMOD or $\triangle \mathrm{CMOD}$ of mixes with different fibre contents (PF1-1.1C and PF1-1.6E) were statistically different. The analysis was conducted for each cycle recorded during the test. Results considering a level of significance $(\alpha)$ of 0.05 showed that the averages were not statistically different despite doubling the fibre content ( $\mathrm{p}$-value $\geq 0.183$ for all cycles). The differences in CMOD response for both compositions were probably eclipsed by the scatter due to fibre distribution and orientation, the production process of samples and associated to the precision of test equipment and set-up [57]. The same was found in the analysis of the influence of the fibre type through the comparison of $\mathrm{PF} 1-1.6 \mathrm{E}$ and PF2-1.5E. By using the same proportion of components and fixing $\mathrm{P}_{\text {upp }}$ in relation to the pre-cracking load, the behaviour in terms of the evolution of the CMOD during the fatigue cycles was not affected by the fibre type and content evaluated in this experimental program.

\subsubsection{Damage evolution}

After the damage localisation, the continuous damage accumulation controls the stressstrain behaviour in the damaged zone [58]. Since specimens are pre-cracked at the beginning of the fatigue test, damage localisation had already taken place so that only damage accumulation occurs. The internal propagation of the damage in the concrete leads to a decrease of the secant modulus, which may reach $60 \%$ of its initial value as the material approaches failure $[59,60]$. This condition may serve as a criterion for predicting the proximity to fatigue failure in concrete.

The dissipated energy in the damaged zone corresponds to the area enclosed by each unloading-reloading cycle, also known as hysteresis loop [61,62]. Figure 4a illustrates the hysteresis loops and Figure $4 \mathrm{~b}$ shows the evolution of the stiffness of the unloading branch and the hysteresis loop area for cycles 1, 500, 10,000, 50,000, 100,000, 500,000, 1,000,000 and 2,000,000 of specimen PF1-1.6E_2M-3. Other specimens behaved similarly. 


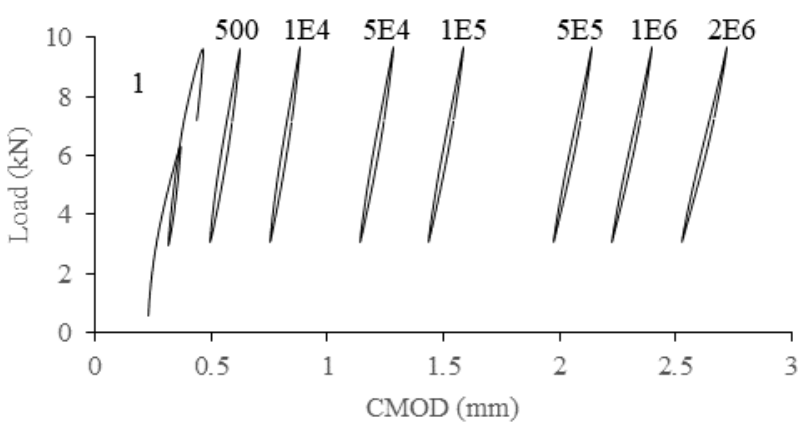

(a)

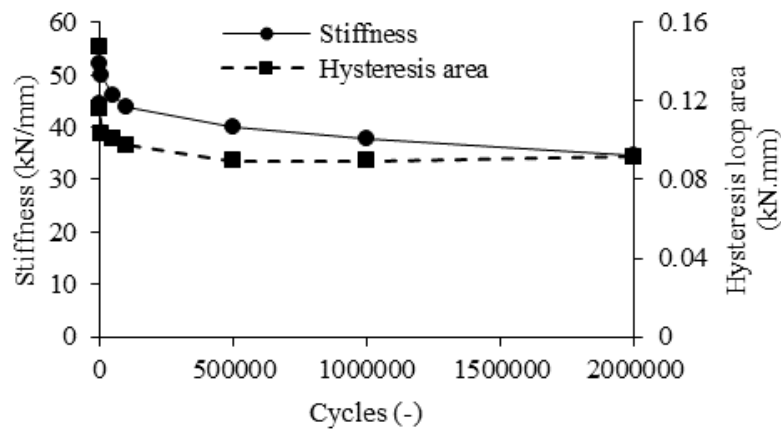

(b)

Figure 4-(a) Hysteresis loops over the cycles and (b) stiffness and hysteresis loop area of specimen PF1-1.6E_2M-3

Except for the first 1,000 cycles, the load-CMOD curve exhibits hysteresis loops with nearly the same area, suggesting a constant energy dissipation due to progressive cracking. The stiffness decreases, which reveals an increase in crack-opening for each load cycle and denotes stiffness degradation $[63,64]$. The stiffness is used to assess the damage ratio (D) in Eq. (1), where $k_{500}$ is the reference stiffness and $k_{n}$ is the stiffness at a given cycle $n$. $k_{500}$ was chosen as a reference to reduce inaccuracies caused by the initial flaws on the fibre-matrix interface on the assessment of the stiffness in the first cycles.

$$
D=1-\left(k_{n} / k_{500}\right)
$$

Figure 5 shows the total $\mathrm{D}$ after 1,000,000 $\left(\mathrm{D}_{1 \mathrm{M}}\right)$ and 2,000,000 $\left(\mathrm{D}_{2 \mathrm{M}}\right)$ cycles. Figure 5 shows the evolution of $\mathrm{D}$ for PF1-1.1C and PF1-1.6E (a) and PF2-1.5E (b). The damage ratio increases rapidly, achieving $65 \%$ of $\mathrm{D}_{1 \mathrm{M}}$ in the first 100,000 cycles. After that, the degradation of the specimens becomes more gradual, increasing only by $15 \%$ from $\mathrm{D}_{1 \mathrm{M}}$ to $\mathrm{D}_{2 \mathrm{M}}$.

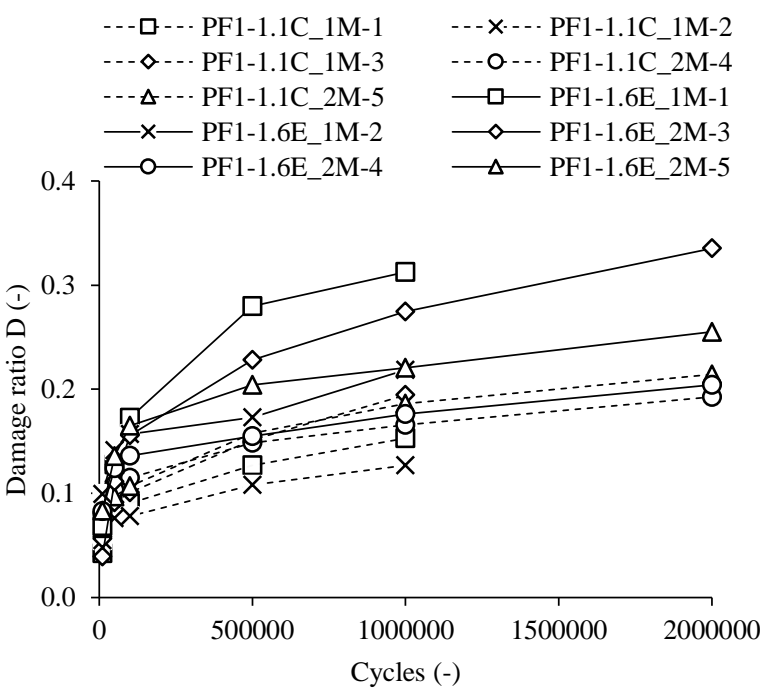

(a)

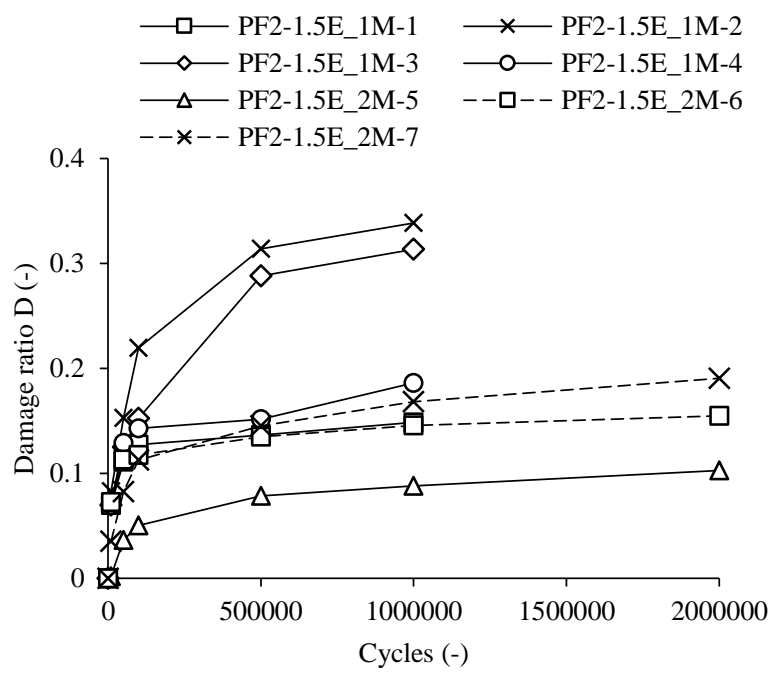

(b)

Figure 5 - Damage ratio versus cycles for PF1-1.1C and PF1-1.6E

The damage ratio of PF1-1.1C and PF1-1.6E were compared to verify if the fibre content influences the stiffness degradation of the specimens. The Welch's $t$-test ( $\alpha$ equal to 0.05 ) reveals 
that the increase in fibre content produces statistically significant differences in the evolution of the average $\mathrm{D}$ over the cycles ( $\mathrm{p}$-value $\leq 0.037$ ). Even though $\mathrm{P}_{\text {upp }}$ was defined in relation to the resistant capacity of each specimen, the bigger load-bearing capacity of PF1-1.6E leads to a proportionally bigger loss of stiffness during the cycles.

\subsection{Remaining residual flexural strength after the fatigue test}

Table 4 presents the maximum residual flexural strength after the fatigue cycles $\left(f_{\text {res,cycl }}\right)$, the CMOD at $f_{\text {res, cycl }}(\mathrm{CMOD}$ Fres,cycl), the corresponding maximum measured in the control quasistatic test $\left(f_{P C, \max }\right.$ and $\left.\mathrm{CMOD}_{f P C, \text { max }}\right)$ and the specific load level ( $\mathrm{S}_{\text {'Fres,cycl }}$ ) calculated as the ratio between $\mathrm{P}_{\text {upp }}$ and the maximum load reached after the fatigue test. $\mathrm{CMOD}_{\text {fres,cycl }}$ is consistently bigger than the measured in the quasi-static control tests $\left(\mathrm{CMOD}_{f P C, \max }\right)$, suggesting that the load cycles displaced the post-fatigue peak stress towards bigger CMOD values. PF1-1.1C exhibited $23 \%$ to $52 \%$ (34\% on average) bigger post-fatigue maximum flexural residual strength than the equivalent control quasi-static tests. By contrast, PF1-1.6E showed $6.9 \%$ smaller values in comparison to the equivalent control quasi-static tests. PF2-1.5E presented $f_{\text {res,cycl }} 6 \%$ bigger than $f_{P C, \max .}$

Figure 6 shows the residual flexural strength curves for the specimens subjected to the fatigue test and the results for the control quasi-static tests of PF1-1.1C (a), PF1-1.6E (b) and PF2$1.5 \mathrm{E}$ (c). The shape of the post-fatigue strength curve resembles and follows the trend found in the quasi-static control tests. Despite the difference expressed in the previous paragraph, notice that most of the stress-CMOD curves for specimens subjected to the fatigue test fall within the range of curves measured in the quasi-static control tests. This suggests that the CMOD increment observed after the load cycles led to a damage level similar to that found in the quasi-static control tests for the same CMOD increment. 


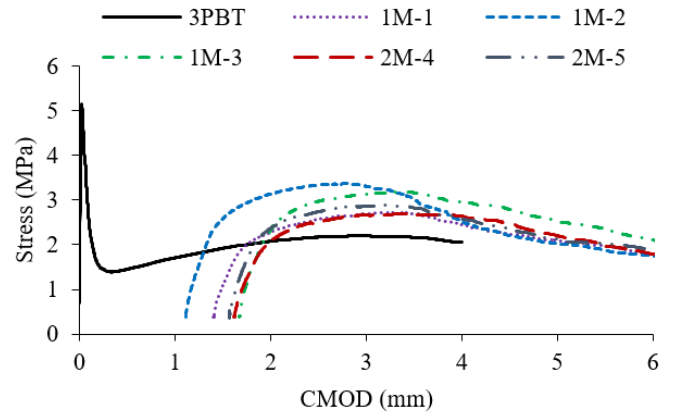

(a)

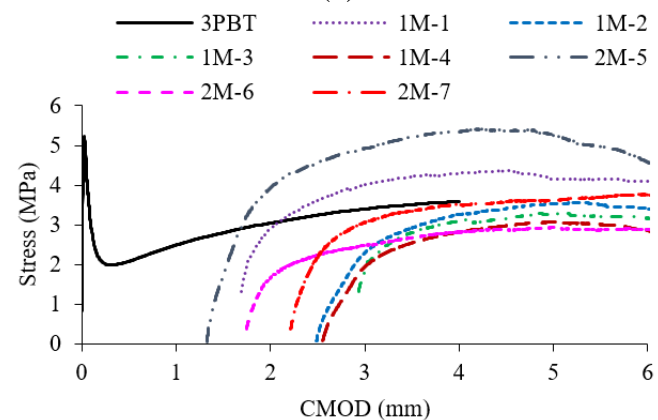

(c)

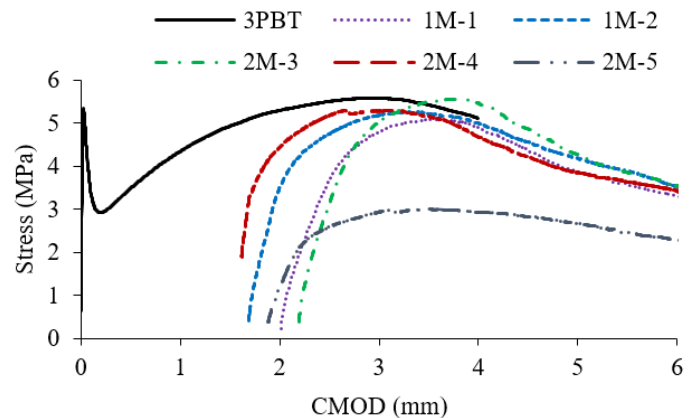

(b)

Figure 6 - Post-fatigue and control quasi-static strength-CMOD curves of (a) PF1-1.1C, (b) PF1-1.6E and (c) PF2$1.5 E$

No significant difference in the post-fatigue maximum strength and the corresponding CMOD was observed between specimens subjected to a $N_{\max }$ of $1,000,000$ or $2,000,000$ cycles. The relatively small level of stiffness degradation between these cycles (only a $15 \%$ decrease in damage ratio) is eclipsed by the scatter observed in the tests. Studies in the literature report an increase in the maximum strength of specimens after load cycles in comparison with specimens subjected only to quasi-static tests $[36,37,54]$. This increase is associated with the application of cyclic load below the endurance limit $[28,29,54,65]$ and depends on the stress ratio during the test (lower stress ratios promote higher post-fatigue strength) $[54,66]$. Such increase is attributed to the consolidation of microvoids at the beginning of the fatigue test [67], the relatively long duration of the tests [59] and the stochastic nature of concrete [46,68]. The similar residual flexural strengths found in specimens characterised before and after the fatigue test do not support the findings by other studies in the literature.

To go deeper in this analysis, Figure 7a shows the relationship between $f_{R 1}$ and the corresponding maximum strength measured in the post-cracking stage $\left(f_{\text {res,cycl }}\right.$ for specimens subjected to the fatigue test or $f_{P C, \max }$ for specimens not subjected to the fatigue test). Notice that $f_{R l}$ was obtained before the fatigue test in all specimens, while the others were obtained either before or after the fatigue test depending on the procedure adopted for each specimen. Should the load cycles affect the resistant capacity of the specimen, the series subjected to the fatigue test would follow a different trendline from those not subjected to the fatigue test in Figure 9a. By contrast, no significant influence of the load cycle on the maximum post-fatigue resistant capacity would be expected if all specimens follow the same trendline. The analysis of Figure 7a confirms this last conjecture, as no clear difference was found regardless of the application or not of the load cycles. 


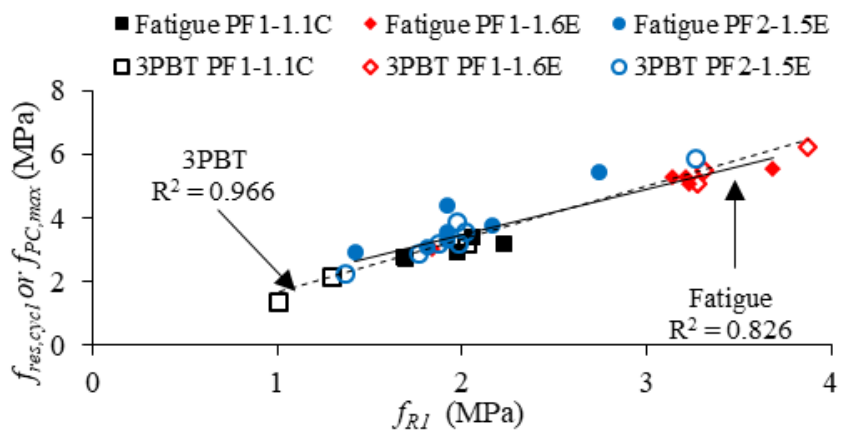

(a)

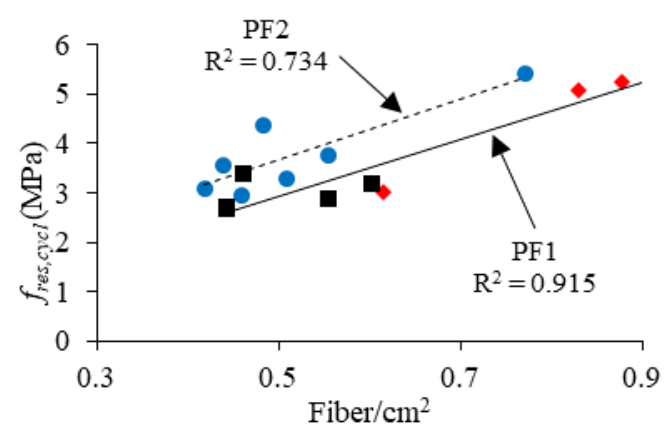

(b)

Figure 7 -Relationship (a) between $f_{\text {res,cycl }}$ or $f_{P C, \max }$ and $f_{R I}$ for specimens subjected to the control or fatigue tests and $(b)$ between $f_{\text {res,cycl }}$ and fibre/ $\mathrm{cm}^{2}$ for specimens subjected to the fatigue test

Specimens PF1-1.6E_2M-5 and PF2-1.5E_2M-5 are considered outliers in their respective series. The difference in behaviour is explained by the number of fibres crossing the fracture crosssection. PF1-1.6E_2M-5 has 26\% fewer fibres than the specimen with the second-lowest number of fibres in the same series and $30 \%$ less than the average of the other specimens in the series. The number of fibres in PF1-1.6E_2M-5 is closer to the average found in PF1-1.1E than in PF1-1.5E, thus explaining why its residual strength after the fatigue test approximates more the former than the latter. The opposite happens with PF2-1.5E_2M-5, which has 39\% more fibres in the fracture surface than the specimen with the second-highest number of fibres in the same series and $61 \%$ more than the average of the other specimens in the series. In this case, the number of fibres is closer to that of PF1-1.6E than to that of PF1-1.6E, thus explaining why the residual strength of PF2-1.5E_2M-5 approximates the former. Figure 7b shows the relationship between the number of fibres in the cross-section and $f_{\text {res,cycl. }}$. The same figure shows the linear regression for results obtained in mixes with PF1 and PF2. As expected, in both cases, there is a linear trend between $f_{\text {res,cycl }}$ and the number of fibres in the cross-section.

\subsection{Visual analysis of fibres on fractured surfaces}

The inspection of the fracture surfaces revealed fibre with two failure modes. Some fibres were pulled out of the matrix and presented surface abrasion (Figure 8a). The fibre tips were not sharpened, and loose particles of the cementitious matrix were attached to it (Figure $8 \mathrm{~b}$ ), revealing the growth of microcracks and matrix damage [69]. Other fibres displayed damage characteristic of significant deformation, with fibrillation and cut tips (Figure 8c and d) [69,70]. Both failure modes were found in all specimens without significant differences regardless of the fibre content, fibre type, maximum number of load cycles or application of load cycles. The lack of evident differences is consistent with the findings in terms of residual strength, which also showed no evident influence of the load cycles on the residual tensile strength. 
(a) PF1

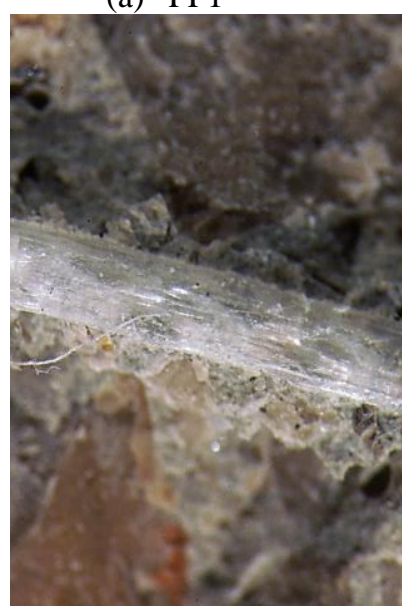

(b) PF2

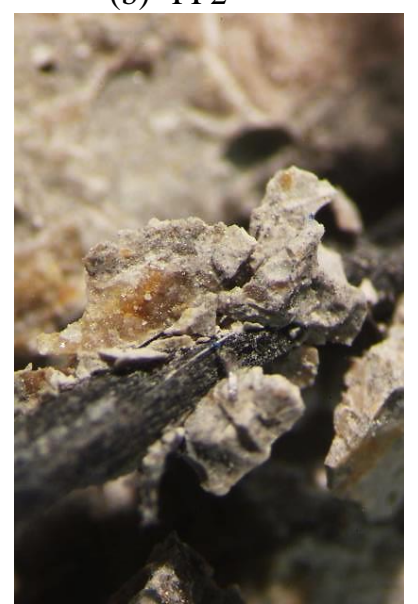

Figure 8-Polypropylene fibres after residual strength test (c) PF1
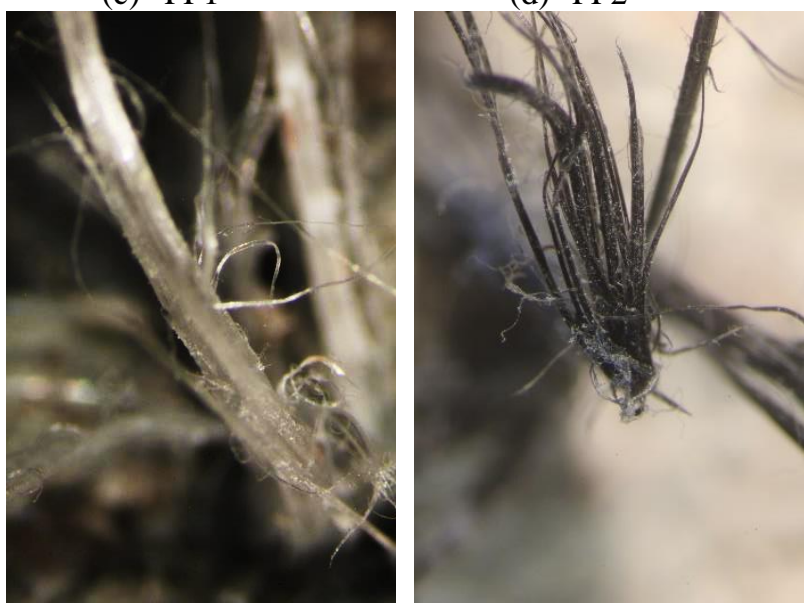

2

\section{CONCEPTUAL MODEL FOR CMOD EVOLUTION}

Figure 11a shows the typical curve that relates the logarithm of the total number of load cycles and the logarithm of CMOD variation between cycles $(d C M O D / d N)$, which is a proxy for the incremental damage induced by the load cycles. This last parameter was calculated for intervals of 1000 cycles to simplify the assessment and reduce the influence of the scatter in the measurements of CMOD. All specimens tested here presented a similar general trend regardless of the fibre type or content. Points tend to align following a straight line until bigger number of cycles are reached, when smaller increments in CMOD are observed (Stage II), and the scatter between cycles leads to more variability in the parameter $\log (d C M O D / d N)$. Despite that, the envelope of the points in this region still follows the linear trend observed initially, as depicted in Figure 11a.
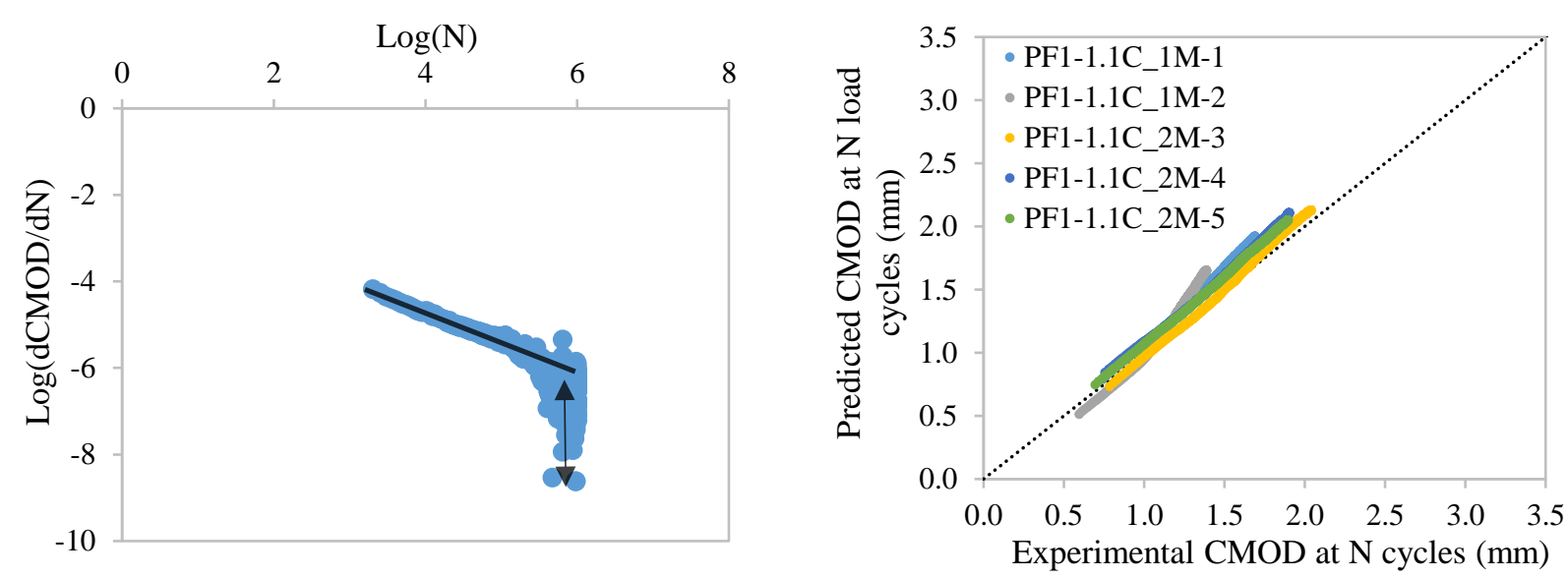

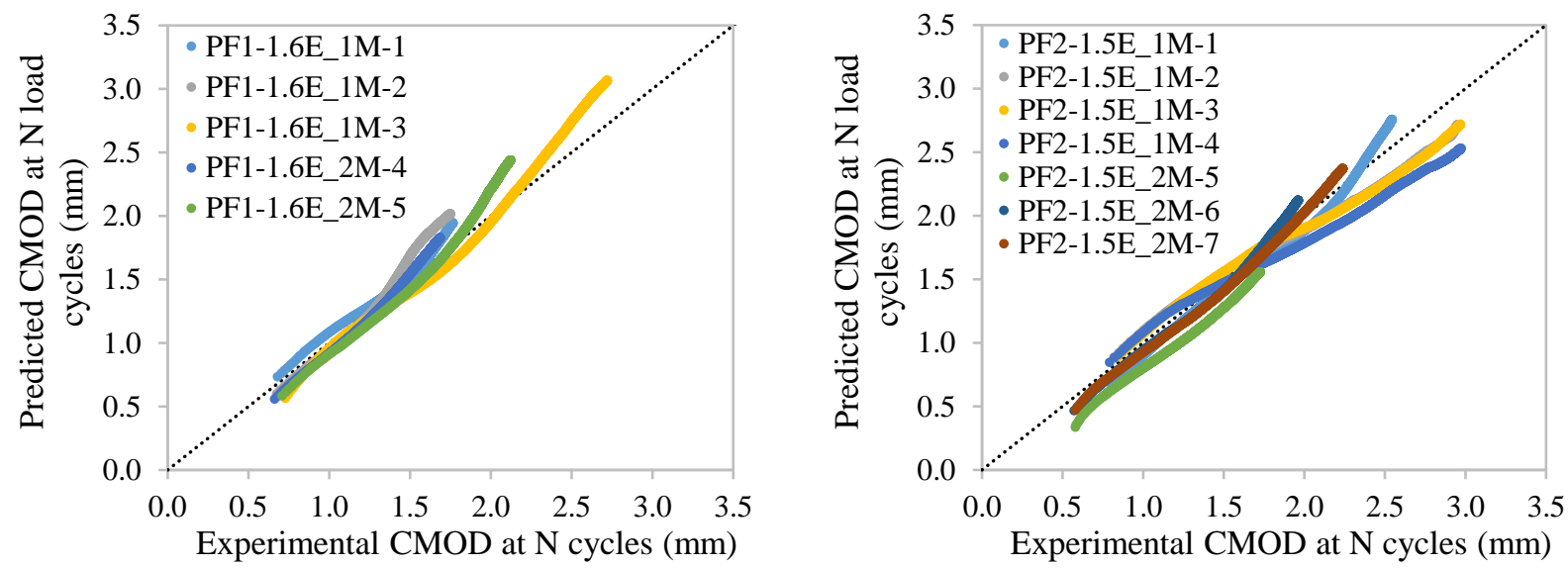

Figure 9 - (a) Typical relationship between number of $\log (d C M O D / d N)$ and $\log (N)$, and experimental versus predicted CMOD for mixes (b) PF1-1.1C, (c) PF1-1.6E and (d) PF2-1.5E

The linear relationship in Figure 11a is represented in Eq. 2, which would allow the prediction of the CMOD of the specimen subjected to the fatigue test. In this equation, $v$ is related to the existing damage induced in the pre-cracking stage and $u$ represents the increase in damage observed over the cycles. $v$ and $u$ are constants that may be determined experimentally by performing a limited number of cycles. Constants were determined for which cyclic load of each specimen. The CMOD after $N$ cycles (represented by $w(N)$ ) is calculated by integrating both sides of Eq. 2 in relation to $d N$, as shown in Eq. 3, as $n$ being the minimum number of cycles.

$$
\log (d C M O D / d N)=u \cdot \log (N)+v
$$

$$
w(N)=\int_{0}^{n} d C M O D=\int_{0}^{n} 10^{v} \cdot N^{u} \cdot d n
$$

The integration gives Eq. 4 for assessing the total crack opening after the fatigue test. The parameter $w_{0}$ marks the initial damage taken as a reference in the test. Since the origin of CMOD was taken before pre-cracking in this experimental programme, $w_{0}$ is 0 . The parameters $k_{1}$ and $k_{2}$ are shown in Eq. 5 and 6, respectively.

$$
\begin{aligned}
& w(N)=k_{1} \cdot n^{k_{2}}+w_{0}=k_{1} \cdot n^{k_{2}} \\
& k_{2}=u+1 \\
& k_{1}=10^{v} / k_{2}
\end{aligned}
$$

An optimisation procedure is proposed to determine when enough cycles have been applied to predict $v$ and $u$ so that the test can be interrupted and the values used to extrapolate the behaviour for a bigger number of cycles using Eq. 4. For a given intermediate cycle $n$ bigger than 500 during the test of a particular specimen, it is possible to estimate $u_{n}$ and $v_{n}$ through the regression of the data up to $n$ cycles using the relationship between $\log (d C M O D / d N)$ and $\log (N)$. These parameters may be used in Eq. 5 and E.q 6 to estimate $k_{1, n}$ and $k_{2, n}$, respectively. Both are used in Eq. 7 to estimate the average prediction error of the points obtained up to $n$ cycles. Once the error 
needed, and the test could be interrupted. Notice that calculations were done considering 500- and 1000-cycle intervals. Since they yielded similar results, only the latter is depicted here.

$$
\operatorname{Error}(n)=\frac{\sum_{N=500}^{n}\left|C M O D_{\text {measured }}-k_{1, n} \cdot N^{k_{2, n}}\right|}{n}
$$

Figures 11b, 11c and 11d shows the measured CMOD and the CMOD estimated with Eq. 4 using the optimisation procedure described above for a limited number of cycles in specimens from compositions $\mathrm{PF} 1-1.1 \mathrm{C}, \mathrm{PF} 1-1.6 \mathrm{E}$ and $\mathrm{PF} 2-1.5 \mathrm{E}$, respectively. All points are situated around the equivalence line with an $\mathrm{R}^{2}$ bigger than 0.9622 , which confirms that the model deducted here (Eq. 4) can adequately reproduce the overall fatigue behaviour even when a limited number of initial cycles are considered in the prediction.

To illustrate the potential of this approach to predict the flexural fatigue behaviour and shorten the fatigue test duration, Table 5 shows the minimum number of cycles $(n)$ required to satisfy the maximum error condition in the optimisation procedure for the early interruption of the test and its proportion regarding the maximum number of cycles applied for each specimen in this experimental program $\left(N_{\max }\right)$. The table shows the error of prediction expected supposing the early interruption of the test after $n$ cycles and the use of parameter $u_{n}$ and $v_{n}$ to predict the CMOD expected at $N_{\max }$. The average error for the whole curve considering the same $u_{n}$ and $v_{n}$ in Eq. 4 and the $\mathrm{R}^{2}$ are also presented in Table 5 .

Table 5 - Minimum number of cycles needed to predict $u_{n}$ and $v_{n}$ using optimisation procedure, error of CMOD prediction for the CMOD at $N_{\max }$ using Eq. $4, R^{2}$ and average error of MOD prediction for whole test

\begin{tabular}{|c|c|c|c|c|c|c|}
\hline \multirow[b]{2}{*}{ Specimen } & \multirow[b]{2}{*}{$N_{\max }$} & \multicolumn{2}{|c|}{$\begin{array}{l}\text { Initial cycles used to } \\
\text { estimate } u_{n} \text { and } v_{n}\end{array}$} & \multirow{2}{*}{$\begin{array}{l}\text { Error of } \\
\text { CMOD } \\
\text { prediction } \\
\text { for } N_{\operatorname{Max}} \\
(\%) \\
\end{array}$} & \multirow{2}{*}{$\begin{array}{l}\text { Average error } \\
\text { of CMOD } \\
\text { prediction for } \\
\text { whole test }(\%)\end{array}$} & \multirow{2}{*}{$\mathbf{R}^{2}$} \\
\hline & & $n$ & $\%$ of $N_{\max }$ & & & \\
\hline PF1-1.1C_2M-5 & 2000000 & 55000 & 2.8 & 8.4 & 7.9 & 0.9994 \\
\hline PF1-1.1C_2M-4 & 2000000 & 253500 & 12.7 & 11.0 & 9.5 & 0.9983 \\
\hline PF1-1.1C_2M-3 & 2000000 & 6000 & 0.3 & 4.6 & 3.6 & 0.9984 \\
\hline PF1-1.1C_1M-2 & 1000000 & 13500 & 1.4 & 19.4 & 12.5 & 0.9886 \\
\hline PF1-1.1C_1M-1 & 1000000 & 20000 & 2.0 & 13.9 & 11.9 & 0.9976 \\
\hline PF1-1.6E_2M-5 & 2000000 & 60500 & 3.0 & 15.1 & 8.3 & 0.9750 \\
\hline PF1-1.6E_2M-4 & 2000000 & 44000 & 2.2 & 8.5 & 5.0 & 0.9924 \\
\hline PF1-1.6E_1M-3 & 1000000 & 200500 & 20.1 & 12.8 & 7.6 & 0.9843 \\
\hline PF1-1.6E_1M-2 & 1000000 & 19500 & 2.0 & 15.5 & 11.6 & 0.9864 \\
\hline PF1-1.6E_1M-1 & 1000000 & 22000 & 2.2 & 10.3 & 5.8 & 0.9622 \\
\hline PF2-1.5E_2M-7 & 2000000 & 155500 & 7.8 & 6.1 & 3.5 & 0.9925 \\
\hline PF2-1.5E_2M-6 & 2000000 & 356000 & 17.8 & 8.4 & 4.6 & 0.9803 \\
\hline PF2-1.5E_2M-5 & 2000000 & 445500 & 22.3 & 9.6 & 14.3 & 0.9929 \\
\hline PF2-1.5E_1M-4 & 1000000 & 12500 & 1.3 & 14.8 & 12.8 & 0.9974 \\
\hline PF2-1.5E_1M-3 & 1000000 & 24500 & 2.5 & 8.3 & 8.3 & 0.9909 \\
\hline PF2-1.5E_1M-2 & 1000000 & 9000 & 0.9 & 7.8 & 8.2 & 0.9946 \\
\hline PF2-1.5E_1M-1 & 1000000 & 285000 & 28.5 & 8.5 & 4.6 & 0.9702 \\
\hline
\end{tabular}


On average, the test can be interrupted after approximately 115000 cycles, which equates to $7.6 \%$ of $N_{\max }$. This represents an average reduction of 13.2 times (ranging from 3.5 to 330 times) on the total duration of the fatigue test. Such reduction and the application of the model from Eq. 4 would entail an average error of prediction of CMOD for $N_{\max }$ of $10.8 \%$. The average error of prediction for the whole curve would be $8.2 \%$, which could be considered acceptable given the high scatter of the test and the significant reduction in the duration of the fatigue test.

\section{CONCLUDING REMARKS}

This study evaluated the mechanical behaviour and the flexural fatigue performance of polypropylene fibre reinforced concrete and proposed a model to predict the crack-opening increase over the cycles. Fatigue tests were performed in pre-cracked specimens with two fibre types and contents to assess the evolution of the crack-opening for prescribed numbers of load cycles. The investigation conducted supports the following conclusions.

- The mechanism of CMOD evolution over the load cycles was similar in all compositions characterised here, regardless of the fibre type or content. The application of a bespoke fatigue loading regime based on the load achieved in the pre-cracking stage of each specimen is one of the factors responsible for this outcome.

- All specimens show a high initial CMOD increase rate over the load cycles, which gradually reduces, reaching an almost constant increase rate. Such behaviour is related to the crack opening required to activate the plastic fibres in the fracture surface. As more fibres become active with bigger CMOD, the sectional resistant capacity increases above the load applied in the fatigue test, thus leading to the reduction in the CMOD increase rate observed. This trend may change if CMOD values above the corresponding to the maximum post-cracking strength are reached. Above this limit, the sectional resistant capacity would be expected to decrease, approaching the fatigue load again and potentially leading to an increment in the CMOD increase rate. This conjecture could not be confirmed in this study as no specimen reached such CMOD values.

- The residual flexural strength of specimens subjected to the fatigue test follows the curve obtained in the quasi-static control tests of equivalent specimens not subjected to the fatigue test. No clear difference was observed in terms of the fracture and fibre pull-out of specimens subjected to 3PBT flexural tests before and after the load cycles. Both findings indicate that the damage induced by the load cycles is equivalent to that observed in the quasi-static control test for the same CMOD increment, which has important repercussions from the design standpoint.

- Supposing that the previous finding applies to bigger elements, the resistant capacity of a structure subjected to load cycles could be estimated by assessing numerically the quasistatic flexural response for the same total CMOD. In other words, the designer would only have to estimate the CMOD expected after the load cycles and apply it in a traditional sectional analysis to assess the remaining resistant capacity. Additional studies with smalland large-scale elements are required to confirm this design approach. 
- The numerical model to predict the fatigue behaviour (Eq. 4) is capable of accurately predicting the CMOD variation over the load cycles, thus aiding the vision described in the previous conclusion. This model depends on parameters related with the initial damage due to pre-cracking $(v)$ and the incremental damage induced by the cycles $(u)$, which could vary depending on the loading regime, pre-cracking level and material characteristics. The optimising procedure proposed here to estimate $v$ and $u$ using a limited number of initial load cycles can enable a significant reduction in the duration of experimental programs about the fatigue of fibre reinforced concrete.

It is important to remark that this work is based on the fatigue response of pre-cracked specimens under service load with particular fibre types and contents. More studies considering additional variables, reversible loading regimes and fatigue tests up to failure should be performed in order to achieve robust recommendations and parameters to account for the effect of fatigue in the design of PFRC structures. Also, other test configuration, as four-point bending test should be consider as the single well defined crack that usually forms under three-point bending might preclude behaviors that might form within distributed cracking under uniform moment.

\section{ACKNOWLEDGMENTS}

The first author thanks the Brazilian National Council for Scientific and Technological Development for the scholarship granted (233980/2014-8). This research was enabled by funds provided by the SAES project (BIA2016-78742-C2-1-R) of Spanish Ministerio de Economía, Industria y Competitividad. Likewise, this work was only possible thanks to the support from the Laboratory of Technology of Structures and Materials "Lluis Agulló" of Polytechnic University of Catalonia.

\section{CONFLICT OF INTEREST}

The authors declare that they have no conflict of interest.

\section{REFERENCES}

[1] A. Conforti, G. Tiberti, G.A. Plizzari, A. Caratelli, A. Meda, Precast tunnel segments reinforced by macrosynthetic fibers, Tunn. Undergr. Sp. Technol. 63 (2017) 1-11. doi:10.1016/j.tust.2016.12.005.

[2] A. de la Fuente, A. Blanco, J. Armengou, A. Aguado, Sustainability based-approach to determine the concrete type and reinforcement configuration of TBM tunnels linings. Case study: Extension line to Barcelona Airport T1, Tunn. Undergr. Sp. Technol. 61 (2017) 179-188. doi:10.1016/j.tust.2016.10.008.

[3] L. Liao, A. de la Fuente, S. Cavalaro, A. Aguado, Design procedure and experimental study on fibre reinforced concrete segmental rings for vertical shafts, Mater. Des. 92 (2016) 590-601. doi:10.1016/j.matdes.2015.12.061.

[4] L. Liao, A. de la Fuente, S. Cavalaro, A. Aguado, Design of FRC tunnel segments considering the ductility requirements of the Model Code 2010, Tunn. Undergr. Sp. Technol. 47 (2015) 200-210. doi:10.1016/j.tust.2015.01.006.

[5] L. Liao, A. de la Fuente, S. Cavalaro, A. Aguado, G. Carbonari, Experimental and analytical study of concrete blocks subjected to concentrated loads with an application to TBM-constructed tunnels, Tunn. Undergr. Sp. Technol. 49 (2015) 295-306. doi:10.1016/j.tust.2015.04.020.

[6] B. Belletti, R. Cerioni, A. Meda, G. Plizzari, Design aspects on steel fiber-reinforced concrete pavements, J. Mater. Civ. Eng. 20 (2008) 599-607. doi:Doi 10.1061/(Asce)0899-1561(2008)20:9(599).

[7] B. Graybeal, UHPC in the US Highway Infrastructure: experience and outlook, in: F. Toutlemonde, J. Resplendino (Eds.), RILEM-Fib-AFGC Int. Symp. Ultra-High Perform. Fibre-Reinforced Concr., Marseille, 
France, 2013: pp. 361-370.

8] Y. Brugeaud, Express bridge deck and light duty bridge, in: F. Toutlemonde, J. Resplendino (Eds.), RILEMFib-AFGC Int. Symp. Ultra-High Perform. Fibre-Reinforced Concr., Marseille, France, 2013: pp. 389-394.

[9] S. Sritharan, G.M. Schmitz, Design of Tall Wind Turbine Towers Utilizing UHPC, in: F. Toutlemonde, J. Resplendino (Eds.), RILEM-Fib-AFGC Int. Symp. Ultra-High Perform. Fibre-Reinforced Concr., Marseille, France, 2013: pp. 433-442.

[10] N. Tapsoba, D. Citek, S. Dobrusky, J. Kolisko, Fatigue Behavior of Ultra-High Performance Concrete (UHPC) Under Compressive Loading, in: F. Toutlemonde, J. Resplendino (Eds.), HPFRC 2017 Des. Build. with UHPFRC New Large-Scale Implementations, Recent Tech. Adv. Exp. Stand., Montpellier, France, 2017: pp. 291-300.

[11] K. Waagaard, Fatigue strength evaluation of offshore concrete structures, IABSE Proc. 6 (1982) 97-115. doi:http://doi.org/10.5169/seals-36662 Nutzungsbedingungen.

[12] J.O. Holmen, Fatigue design evaluation of offshore concrete structures, Matériaux Constr. 17 (1984) 39-42. doi:10.1007/BF02474054.

[13] T.M. Abu-Lebdeh, G.Z. Voyiadjis, Plasticity-Damage Model for Concrete under Cyclic Multiaxial Loading, J. Eng. Mech. 119 (1993) 1465-1484. doi:10.1061/(ASCE)0733-9399(1993)119:7(1465).

[14] A. Malek, A. Scott, S. Pampanin, G. MacRae, S. Marx, Residual Capacity and Permeability-Based Damage Assessment of Concrete under Low-Cycle Fatigue, J. Mater. Civ. Eng. 30 (2018) 04018081. doi:10.1061/(ASCE)MT.1943-5533.0002248.

[15] S. Blasón, E. Poveda, G. Ruiz, H. Cifuentes, A. Fernández Canteli, Twofold normalization of the cyclic creep curve of plain and steel-fiber reinforced concrete and its application to predict fatigue failure, Int. J. Fatigue. 120 (2019) 215-227. doi:10.1016/j.ijfatigue.2018.11.021.

[16] J. Zhang, H. Stang, V.C. Li, Fatigue life prediction of fiber reinforced concrete under flexural load, Int. J. Fatigue. 21 (1999) 1033-1049. doi:10.1016/S0142-1123(99)00093-6.

[17] N.K. Banjara, K. Ramanjaneyulu, Experimental Investigations and Numerical Simulations on the Flexural Fatigue Behavior of Plain and Fiber-Reinforced Concrete, J. Mater. Civ. Eng. 30 (2018) 04018151. doi:10.1061/(ASCE)MT.1943-5533.0002351.

[18] B. Isojeh, M. El-Zeghayar, F.J. Vecchio, Concrete Damage under Fatigue Loading in Uniaxial Compression, ACI Mater. J. 114 (2017). doi:10.14359/51689477.

[19] L. Xu, B. Li, X. Ding, Y. Chi, C. Li, B. Huang, Y. Shi, Experimental Investigation on Damage Behavior of Polypropylene Fiber Reinforced Concrete under Compression, Int. J. Concr. Struct. Mater. 12 (2018) 68. doi:10.1186/s40069-018-0302-3.

[20] D.C. González, R. Moradillo, J. Mínguez, J.A. Martínez, M.A. Vicente, Postcracking residual strengths of fiber-reinforced high-performance concrete after cyclic loading, Struct. Concr. 19 (2018) 340-351. doi:10.1002/suco.201600102.

[21] S.P. Shah, Predictions of comulative damage for concrete and reinforced concrete, Matériaux Constr. 17 (1984) 65-68. doi:10.1007/BF02474059.

[22] S. Cangiano, G.A. Plizzari, V. Slowik, Experimental investigation into the fatigue crack growth in concrete, in: Fract. Mech. Concr. Struct. Proc. Fram., 1996: pp. 645-654.

[23] T. Makita, E. Brühwiler, Tensile fatigue behaviour of ultra-high performance fibre reinforced concrete (UHPFRC), Mater. Struct. 47 (2014) 475-491. doi:10.1617/s11527-013-0073-x.

[24] J. Zhang, H. Stang, V.C. Li, Experimental Study on Crack Bridging in FRC under Uniaxial Fatigue Tension, J. Mater. Civ. Eng. 12 (2000) 66-73. doi:10.1061/(ASCE)0899-1561(2000)12:1(66).

[25] G.A. Plizzari, S. Cangiano, S. Alleruzzo, The fatigue behaviour of cracked concrete, Fatigue Fract. Eng. Mater. Struct. 20 (1997) 1195-1206. doi:10.1111/j.1460-2695.1997.tb00323.x.

[26] A. Medeiros, X. Zhang, G. Ruiz, R.C. Yu, M.D.S.L. Velasco, Effect of the loading frequency on the compressive fatigue behavior of plain and fiber reinforced concrete, Int. J. Fatigue. 70 (2015) 342-350. doi:10.1016/j.ijfatigue.2014.08.005.

[27] F. Germano, G. Tiberti, G. Plizzari, Post-peak fatigue performance of steel fiber reinforced concrete under flexure, Mater. Struct. 49 (2016) 4229-4245. doi:10.1617/s11527-015-0783-3.

[28] G. Chanvillard, P. Pimienta, A. Pineaud, P. Rivillon, Fatigue flexural behaviour of pre-cracked specimens of Ductal ${ }^{\circledR}$ UHPFRC, in: M. Di Prisco, R. Felicetti, G.A. Plizzari (Eds.), 6th Int. RILEM Symp. Fibre-Reinforced Concr., 2004: p. 16.

[29] A.E. Naaman, H. Hammoud, Fatigue characteristics of high performance fiber-reinforced concrete, Cem. Concr. Compos. 20 (1998) 353-363. doi:10.1016/S0958-9465(98)00004-3.

[30] D.M. Carlesso, A. de la Fuente, S.H.P. Cavalaro, Fatigue of cracked high performance fiber reinforced concrete 
[31] V.M. de Alencar Monteiro, L.R. Lima, F. de Andrade Silva, On the mechanical behavior of polypropylene, steel and hybrid fiber reinforced self-consolidating concrete, Constr. Build. Mater. 188 (2018) 280-291. doi:10.1016/j.conbuildmat.2018.08.103.

[32] R. Bedi, S.P. Singh, R. Chandra, Design Fatigue Lives of Polypropylene Fibre Reinforced Polymer Concrete Composites, J. Mater. Eng. Struct. 1 (2014) 99-109. http://revue.ummto.dz/index.php/JMES/article/view/192.

[33] M.R. Mohamadi, J.A. Mohandesi, M. Homayonifar, Fatigue behavior of polypropylene fiber reinforced concrete under constant and variable amplitude loading, J. Compos. Mater. 47 (2013) 3331-3342. doi:10.1177/0021998312464083.

[34] H. Zhang, K. Tian, Properties and mechanism on flexural fatigue of polypropylene fiber reinforced concrete containing slag, J. Wuhan Univ. Technol. Mater. Sci. Ed. 26 (2011) 533-540. doi:10.1007/s11595-011-02638 .

[35] H. Li, M. hua Zhang, J. ping Ou, Flexural fatigue performance of concrete containing nano-particles for pavement, Int. J. Fatigue. 29 (2007) 1292-1301. doi:10.1016/j.ijfatigue.2006.10.004.

[36] V. Ramakrishnan, G.Y. Wu, G. Hosalli, Flexural Fatigue Strength, Endurance Limit, and Impact Strength of Fiber Reinforced Concretes, Transp. Res. Rec. J. Transp. Res. Board. 1226 (1989) 17-24.

[37] M. Nagabhushanam, V. Ramakrishnan, G. Vondran, Fatigue Strength of Fibrillated Polypropylene Fiber Reinforced Concretes, Transp. Res. Rec. 1226 (1989) 36-47.

[38] K.C. Dao, Fatigue failure mechanisms in polymer composites, Polym. Compos. 3 (1982) 12-17. doi:10.1002/pc.750030104.

[39] T. Matsumoto, Effect of fiber fatigue rupture on monotonic and cyclic crack bridging laws in discontinuous fiber reinforced composites, J. Appl. Mech. 11 (2008) 891-902. doi:10.2208/journalam.11.891.

[40] A. Muliana, Nonlinear viscoelastic-degradation model for polymeric based materials, Int. J. Solids Struct. 51 (2014) 122-132. doi:10.1016/j.ijsolstr.2013.09.016.

[41] S.K. Samal, S. Mohanty, S.K. Nayak, Polypropylene-Bamboo/Glass Fiber Hybrid Composites: Fabrication and Analysis of Mechanical, Morphological, Thermal, and Dynamic Mechanical Behavior, J. Reinf. Plast. Compos. 28 (2009) 2729-2747. doi:10.1177/0731684408093451.

[42] M.A.L. Manchado, L. Valentini, J. Biagiotti, J.M. Kenny, Thermal and mechanical properties of single-walled carbon nanotubes-polypropylene composites prepared by melt processing, Carbon N. Y. 43 (2005) 1499-1505. doi:10.1016/j.carbon.2005.01.031.

[43] M.A. López-Manchado, M. Arroyo, Thermal and dynamic mechanical properties of polypropylene and short organic fiber composites, Polymer (Guildf). 41 (2000) 7761-7767. doi:10.1016/S0032-3861(00)00152-X.

[44] J. Son, D.J. Gardner, S. O'Neill, C. Metaxas, Understanding the viscoelastic properties of extruded polypropylene wood plastic composites, J. Appl. Polym. Sci. 89 (2003) 1638-1644. doi:10.1002/app.12372.

[45] M. Tajvidi, R.H. Falk, J.C. Hermanson, Effect of natural fibers on thermal and mechanical properties of natural fiber polypropylene composites studied by dynamic mechanical analysis, J. Appl. Polym. Sci. 101 (2006) 4341-4349. doi:10.1002/app.24289.

[46] Fib, International Federation for Structural Concrete fib Model Code for Concrete Structures 2010, Germany, 2013.

[47] F.A. Farhat, D. Nicolaides, A. Kanellopoulos, B.L. Karihaloo, High performance fibre-reinforced cementitious composite (CARDIFRC) - Performance and application to retrofitting, Eng. Fract. Mech. 74 (2007) 151-167. doi:10.1016/j.engfracmech.2006.01.023.

[48] S.F. Breña, M.A. Benouaich, M.E. Kreger, S.L. Wood, Fatigue tests of reinforced concrete beams strengthened using carbon fiber-reinforced polymer composites, ACI Struct. J. 102 (2005) 305-313. doi:10.14359/14282.

[49] F. de Andrade Silva, B. Mobasher, R.D.T. Filho, Fatigue behavior of sisal fiber reinforced cement composites, Mater. Sci. Eng. A. 527 (2010) 5507-5513. doi:10.1016/j.msea.2010.05.007.

[50] A. Nanni, Fatigue behaviour of steel fiber reinforced concrete, Cem. Concr. Compos. 13 (1991) 239-245. doi:10.1016/0958-9465(91)90029-H.

[51] M. Tarifa, X. Zhang, G. Ruiz, E. Poveda, Full-scale fatigue tests of precast reinforced concrete slabs for railway tracks, Eng. Struct. 100 (2015) 610-621. doi:10.1016/j.engstruct.2015.06.016.

[52] C.D. Johnston, R.W. Zemp, Flexural Fatigue Performance of Steel Fiber Reinforced Concrete--Influence of Fiber Content, Aspect Ratio, and Type, ACI Mater. J. 88 (1991) 374-383. doi:10.14359/1875.

[53] S. Arora, S.P. Singh, Analysis of flexural fatigue failure of concrete made with $100 \%$ Coarse Recycled Concrete Aggregates, Constr. Build. Mater. 102 (2016) 782-791. doi:10.1016/j.conbuildmat.2015.10.098.

[54] E. Parant, P. Rossi, C. Boulay, Fatigue behavior of a multi-scale cement composite, Cem. Concr. Res. 37 (2007) 264-269. doi:10.1016/j.cemconres.2006.04.006. 
[55] B.H. Oh, J.C. Kim, Y.C. Choi, Fracture behavior of concrete members reinforced with structural synthetic fibers, Eng. Fract. Mech. 74 (2007) 243-257. doi:10.1016/j.engfracmech.2006.01.032.

[56] Fib, International Federation for Structural Concrete. Constitutive modelling of high strength/high performance concrete, Germany, 2008.

[57] S.H.P. Cavalaro, A. Aguado, Intrinsic scatter of FRC: an alternative philosophy to estimate characteristic values, Mater. Struct. Constr. 48 (2015) 3537-3555. doi:10.1617/s11527-014-0420-6.

[58] B. Mu, K. V. Subramaniam, S.P. Shah, Failure Mechanism of Concrete under Fatigue Compressive Load, J. Mater. Civ. Eng. 16 (2004) 566-572. doi:10.1061/(asce)0899-1561(2004)16:6(566).

[59] fib Federation Internacionale du beton, Bond of reinforcement in concrete - State-of-the-art report, 2000.

[60] J.-F. Destrebecq, Cyclic and Dynamic Loading Fatigue of Structural Concrete, in: Mech. Behav. Concr., John Wiley \& Sons, Inc., Hoboken, NJ USA, 2013: pp. 185-224. doi:10.1002/9781118557587.ch5.

[61] K. Gylltoft, A fracture mechanics model for fatigue in concrete, Matériaux Constr. 17 (1984) 55-58. doi:10.1007/BF02474057.

[62] S. V. Kolluru, E.F. O’Neil, J.S. Popovics, S.P. Shah, Crack Propagation in Flexural Fatigue of Concrete, J. Eng. Mech. 126 (2000) 891-898. doi:10.1061/(ASCE)0733-9399(2000)126:9(891).

[63] B. Boulekbache, M. Hamrat, M. Chemrouk, S. Amziane, Flexural behaviour of steel fibre-reinforced concrete under cyclic loading, Constr. Build. Mater. 126 (2016) 253-262. doi:10.1016/j.conbuildmat.2016.09.035.

[64] C. Carloni, K. V. Subramaniam, Investigation of sub-critical fatigue crack growth in FRP/concrete cohesive interface using digital image analysis, Compos. Part B Eng. 51 (2013) 35-43. doi:10.1016/j.compositesb.2013.02.015.

[65] V. Ramakrishnan, C. Mayer, A.E. Naaman, Cyclic behaviour, fatigue strength, endurance limit and models for fatigue behavior of FRC, Chapter. 4 (2014) 101-148.

[66] V. Ramakrishnan, C. Sivakumar, Constitutive model for prediction of flexural fatigue life and performance characteristics of polyolefin fiber reinforced concrete, in: H.W. Reinhardt, A.E. Naaman (Eds.), Int. RILEM Conf. High Perform. Fiber Reinf. Cem. Compos. (HPFRCC 3), Mainz, 1999: pp. 299-320.

[67] B. Zhang, K. Wu, Residual fatigue strength and stiffness of ordinary concrete under bending, Cem. Concr. Res. 27 (1997) 115-126. doi:10.1016/S0008-8846(96)00183-4.

[68] L. Lohaus, N. Oneschkow, M. Wefer, Design model for the fatigue behaviour of normal-strength, high-strength and ultra-high-strength concrete, Struct. Concr. 13 (2012) 182-192. doi:10.1002/suco.201100054.

[69] S. Müller, V. Mechtcherine, Fatigue behaviour of strain-hardening cement-based composites (SHCC), Cem. Concr. Res. 92 (2017) 75-83. doi:10.1016/j.cemconres.2016.11.003.

[70] J. Qiu, E.-H. Yang, Study on fatigue failure of polymeric fiber-reinforced strain-hardening cementitious composites, in: 3rd Int. Rilem Conf. Strain Hardening Cem. Compos. Dordrecht, Netherlands, 2014: pp. 145153. 